\title{
Historical and contemporary determinants of global phylogenetic structure in tropical reef fish faunas
}

\author{
Fabien Leprieur, Simona Colosio, Patrice Descombes, Valeriano Parravicini, Michel Kulbicki, \\ Peter F. Cowman, David R. Bellwood, David Mouillot and Loïc Pellissier
}

F. Leprieur (fabien.leprieur@univ-montp2.fr) and D. Mouillot, UMR MARBEC (CNRS, IRD, IFREMER, UM), Univ. Montpellier 2, Place Eugène Bataillon, FR-34095 Montpellier Cedex 5, France. - S. Colosio, P. Descombes and L. Pellissier, Univ. of Fribourg, Unit of Ecology and Evolution, Ch. du Musée 10, CH-1700 Fribourg, Switzerland. PD and LP also at: Swiss Federal Research Inst. WSL, CH-8903 Birmensdorf, Switzerland, and Landscape Ecology, Inst. of Terrestrial Ecosystems, ETH Zürich, Zürich, Switzerland. - V. Parravicini, USR 3278 CNRS-EPHE CRIOBE, Univ. of Perpignan, FR-66860 Perpignan Cedex, France. - M. Kulbicki, Inst. de Recherche pour le Développement, UR 227 CoReUs, LABEX Corail, Laboratoire Arago, BP 44, FR-66651 Banyuls/mer, France. - P. F. Cowman, Dept of Ecology and Evolutionary Biology, Yale Univ., 21 Sachem St, New Haven, CT 06511, USA. - D. R. Bellwood and DM, ARC Centre of Excellence for Coral Reef Studies, and School of Marine and Tropical Biology, James Cook Univ., Townsville, QLD 4811, Australia.

\begin{abstract}
Identifying the main determinants of tropical marine biodiversity is essential for devising appropriate conservation measures mitigating the ongoing degradation of coral reef habitats. Based on a gridded distribution database and phylogenetic information, we compared the phylogenetic structure of assemblages for three tropical reef fish families (Labridae: wrasses, Pomacentridae: damselfishes and Chaetodontidae: butterflyfishes) using the net relatedness (NRI) and nearest taxon (NTI) indices. We then related these indices to contemporary and historical environmental conditions of coral reefs using spatial regression analyses. Higher levels of phylogenetic clustering were found for fish assemblages in the Indo-Australian Archipelago (IAA), and more particularly when considering the NTI index. The phylogenetic structure of the Pomacentridae, and to a lower extent of the Chaeotodontidae and Labridae, was primarily associated with the location of refugia during the Quaternary period. Phylogenetic clustering in the IAA may partly result from vicariance events associated with coral reef fragmentation during the glacial periods of the Quaternary. Variation in the patterns among fish families further suggest that dispersal abilities may have interacted with past habitat availability in shaping the phylogenetic structure of tropical reef fish assemblages.
\end{abstract}

Coral reefs support the greatest biodiversity of marine fishes, but this biodiversity is not evenly distributed across oceans with a peak in the Indo-Australian Archipelago (IAA; Bellwood et al. 2005, Pellissier et al. 2014), and the mechanisms underpinning the origin of this pattern are only partially understood (Bellwood et al. 2005, Bowen et al. 2013, Pellissier et al. 2014). Currently, coral reefs are globally affected by climate change (Hoegh-Guldberg et al. 2007, Pandolfi et al. 2011) and multiple anthropic stressors (e.g. habitat degradation, pollution, overfishing) as they are found in some of the most disturbed coastal zones on Earth (Hughes et al. 2003). Given the present escalation of threats, and the associated biodiversity erosion, a better understanding of the processes that generate and maintain the biodiversity of coral reef fishes is urgently needed.

Species assemblage in a given place and time can be the result of a range of processes, whose relative contribution is debated among ecologists and biogeographers (Mittelbach et al. 2007). These processes can be generally divided into those related to contemporary ecological conditions (Götzenberger et al. 2012, Hughes et al. 2012) and those related to evolutionary history and past environmental changes (Graham et al. 2006, Kissling et al. 2012). Among ecological processes, those related to environmental filtering and competition have been widely studied by assessing whether species in a given area are phylogenetically more (clustering) or less (overdispersion) closely related to each other than would be expected by chance or whether these species are a random subset of the regional pool of species (Webb 2000, Webb et al. 2002). The use of phylogenetic relatedness to inform on contemporary ecological processes is based on the assumption that species ecological differences are proportional to the amount of time since they diverged from a common ancestor (Webb et al. 2002). As a consequence, closely related species should share similar biological attributes that define the capacity of species to persist within communities in a given environment (Graham et al. 2009) or under varying competitive pressure (Cavender-Bares et al. 2004). However, phylogenetic relatedness between species may be not a relevant proxy of their biological relatedness if species traits are not phylogenetically conserved (e.g. trait lability resulting from convergent evolution; Losos 2008), 
which may blur the interpretation of the role of environmental filtering vs competition in shaping assemblage structure (Swenson 2009). In addition, the phylogenetic structure of assemblages may not reflect ongoing ecological processes but rather the legacy of historical and evolutionary processes (Cardillo 2011, Kissling et al. 2012, Cantalapiedra et al. 2014).

The role of historical and evolutionary processes in shaping the phylogenetic structure of assemblages is recognized both in regards to phylogenetic clustering and overdispersion of assemblages (Wiens and Donoghue 2004). In situ diversification within isolated regions such as biogeographic regions may result in an assemblage where species are more closely related than in the global pool of species (Kissling et al. 2012). In the case of palms (Kissling et al. 2012) or large ruminant mammals (Cantalapiedra et al. 2014), long term geographic isolation has shaped patterns of phylogenetic clustering worldwide, where on distinct continents closely related species have colonized contrasted sub-regions or biomes (Cardillo 2011). Historical formations of geographic barriers such as mountain ranges have also shaped contrasted phylogenetic structure of species assemblages (Graham et al. 2009). It has been further suggested that the frequency and magnitude of earth processes during the Tertiary and Quaternary periods, such as climatic fluctuations or continental drift, have likely been decisive in shaping the present-day phylogenetic structure of species assemblages (Hortal et al. 2011).

In the marine realm, historical and evolutionary processes can also explain contemporary patterns of species assemblage structure. For instance, the fractioning of populations into differentiated lineages as a result of the geological complexity of the region (Renema et al. 2008, Cowman and Bellwood 2013a) and eustatic sea level changes (McManus 1985, Ludt and Rocha 2015) may have shaped the biodiversity of coral reefs. For instance, Quaternary climate fluctuations of available coral reef habitat for reef fishes largely explain richness patterns worldwide (Pellissier et al. 2014). During cycles of global cooling, and following temperature and sea level shifts, coral reef habitats were only maintained in some refugia, where environmental conditions remained favourable for their development (Pellissier et al. 2014), but isolated from each other by barriers potentially promoting allopatric or parapatric speciation (McManus 1985, Potts 1985). The Indo-Pacific region, and more particularly the IAA, maintained extensive coral reef refugia during cold periods while the Atlantic had only very limited areas suitable for coral reefs, implying a further degradation of Caribbean coral reefs after the onset of glaciations following the Panama closure (O'Dea et al. 2007). These disparate environmental histories are strongly reflected in the evolution of reef fishes among the major coral reef realms (Cowman and Bellwood 2013a). Historical processes during the Quaternary promoting the rise and fall of species are therefore expected to have played a major role in shaping global patterns of phylogenetic structure in tropical reef associated species.

Here, we mapped the phylogenetic structure of tropical reef fish assemblages globally using a grid-based database on tropical reef fish distribution (Pellissier et al. 2014) and the phylogenies of three reef fish families, namely Pomacentridae, Chaetodontidae and Labridae (Cowman and Bellwood
2011). We focused on these families because 1) they are among the most widespread, diverse and abundant on coral reefs globally (Bellwood and Wainwright 2002), 2) the current phylogenetic resolution within each family comes from over a decades worth of sequencing and phylogenetic effort across the ichthyological community (Pomacentridae: Tang 2001, Jang-liaw et al. 2002, Quenouille et al. 2004, Cooper et al. 2009, Chaetodontidae: McMillan and Palumbi 1995, Fessler and Westneat 2007, Bellwood et al. 2010, Labridae: Barber and Bellwood 2005, Read et al. 2006, Smith et al. 2008, Kazancioglu 2009), and 3) they display highly contrasted dispersal and colonization abilities (Luiz et al. 2013). Pomacentridae have low sustained swimming ability of late pelagic stage, are demersal spawners (Luiz et al. 2013) and frequently show high biotic dependency to coral reef habitat (Litsios et al. 2012). Clades with low dispersal abilities seem to be more subject to allopatric speciation promoting diversification (Sandel and Dangremond 2012) and comparing phylogenetic structure across clades allows better documentation of the mechanisms underpinning species formation and assembly. We then investigated whether contemporary or historical environmental conditions best explain spatial variation in the phylogenetic structure of tropical reef fish assemblages. For instance, if allopatric or parapatric speciation across multiple refugia during periods of isolation, is the major factor shaping phylogenetic structure of tropical reef fish assemblages, phylogenetic clustering should be more important in proximity to stable (but fragmented) coral reef refugia concentrated in the IAA (Pellissier et al. 2014). In contrast, if contemporary ecological processes such as environmental filtering shape phylogenetic structure of assemblages, we can expect increasing phylogenetic clustering along environmental gradients, and more particularly towards cold temperatures at higher latitudes (Qian and Jiang 2014). Contemporary environmental filtering based on climatic tolerances conserved across lineages (i.e. phylogenetic niche conservatism) would be therefore the main force structuring assemblages.

\section{Methods}

\section{Global distribution of tropical reef fishes}

We obtained information on presence/absence of reef fish at 169 locations worldwide examining almost 500 references and extracting information from published works, regional checklists, monographs on specific families or genera, and reports (Parravicini et al. 2013). To increase the homogeneity of information among species lists, we focused our analysis on shallow water species (between 0 and $75 \mathrm{~m}$ depth). Overall, we obtained information on the distribution of 6316 reef fishes. As lists of each of the 169 locations are unlikely to have complete lists of the species that occur there, we constructed an extent of occurrence map for each species, defined as the convex hull polygon of the locations where each species was present. Species composition was then extracted from grid cells of $5^{\circ} \times 5^{\circ}$, corresponding to approximately $555 \times 555 \mathrm{~km}$ at the equator. The grain size of the grid of $5^{\circ} \times 5^{\circ}$ was chosen because it represents a good compromise between the desired resolution and the geographical density 
of information. We excluded from our analyses all cells not containing coral reef for shallow water species. Bathymetric data were obtained from the SRTM30_PLUS bathymetry (Shuttle Radar Topography Mission, available at: <http:// topex.ucsd.edu/WWW_html/srtm30_plus.html >) while information on the distribution of coral reefs was obtained from available information partially based on the Millenium Coral Reef Mapping project and downloadable at: <http:// data.unep-wcmc.org $>$. We also removed cells with more than $90 \%$ of the surface inland. We additionally excluded those cells corresponding to areas were we had an original gap of information. These include the cells corresponding to the Gulf of Mexico, the estuary of the Amazon River and few cells in the NW part of Australia. From this database, we extracted the occurrences of nearly all known species for the Labridae $(n=567)$, Chaetodontidae $(n=127)$ and Pomacentridae $(\mathrm{n}=371)$ families.

\section{Fish phylogenies}

We used the dated phylogenies of the three families published in Cowman and Bellwood (2011) comprising 278 species out of the 567 reef Labrid species, 96 out of 127 species for the Chaetodontidae family, and 176 out of 371 species for the Pomacentridae family. These phylogenies and related information (i.e. information on taxa sampled in each family, accession number for GenBank sequences, and primary publication source) are available at $<$ http:// datadryad.org/resource/doi:10.5061/dryad.m8s502qb >. We incorporated other species by grafting new tips onto the backbone phylogenies based on published phylogenies for these families at lower taxonomic scale, supplemented by taxonomic information from fish identification guides (Supplementary material Appendix 1) and FishBase (<www. fishbase.org $>$ ). Where information allowed, new tips representing unsampled species were added to direct sister species or to the base of the clade representing its genus. Tips were added using the bind.tip () function implemented in the R package 'phytools' (Revell 2012). The resulting polytomies were subsequently randomly resolved using a birthdeath model following the procedure proposed by Kuhn et al. (2011) in R (R Development Core Team) and BEAST (Drummond et al. 2012). More specifically, 11111000 permutations were runs and the trees were sampled at every 1000th permutation. At each permutation, the first $10 \%$ trees were discarded as burn-in, hence yielding a posterior distribution of 10000 trees from which we randomly sampled 1000 trees for use in a sensitivity analysis (see below).

\section{Phylogenetic assemblage structure metrics}

For each grid cell and for each family, we characterized the phylogenetic structure of fish assemblages using two metrics: the net relatedness index (NRI) and the nearest taxon index (NTI) as standardized values of the mean pairwise distance (MPD) and the mean nearest taxon distance (MNTD), respectively (Webb 2000, Webb et al. 2002). MPD represents the mean pairwise phylogenetic distance between all species in each assemblage, while MNTD represents the mean phylogenetic distance separating each species in the assemblage from its closest relative. NRI and NTI were computed as standardized effect sizes, i.e. by comparing the MPD and MNTD values in the observed assemblages to those generated by shuffling 999 times the names of taxa across the tips of the phylogeny. This frequently used null model (Kissling et al. 2012, Cantalapiedra et al. 2014) allows randomizing the relatedness of species to one another, while maintaining species occurrence frequency and species richness. Positive NRI and NTI values indicate that assemblages are phylogenetically clustered, i.e. that species are more closely related than expected, while negative values indicate phylogenetic overdispersion, i.e. that species are more distantly related than expected. The use of the two metrics is complementary as NRI is more sensitive to phylogenetic tree-wide patterns while NTI to patterns towards the tips of the tree (Webb 2000, Webb et al. 2002). NTI is indeed calculated from the tips of the phylogeny and hence reflects the terminal phylogenetic structure of assemblages while NRI reflects the basal phylogenetic structure of assemblages (Webb 2000, Webb et al. 2002). In the context of hypothesis testing, NTI is therefore more relevant than NRI for evaluating the influence of recent historical events (e.g. during the Quaternary period).

Both NRI and NTI are potentially sensitive to the definition of the species pool (Cardillo 2011, Cantalapiedra et al. 2014). For instance, recent studies emphasized the need to explicitly define biogeographical species pools to tease apart the relative roles of historical vs. ecological factors in shaping assemblage structure (Cantalapiedra et al. 2014). In the present study, we first considered the global pool of tropical reef fishes and then the species pool of Indo-Pacific region only, hence excluding the Atlantic and Tropical Eastern Pacific faunas. Indeed, the tropical reef fish fauna of the Indo-Pacific region (including the IAA hotspot) display a different biogeographical history compared to the Atlantic and Tropical Eastern Pacific regions (Cowman and Bellwood 2013a, b).

In the above analyses, we used a phylogenetic tree with a number of polytomies. We therefore performed a sensitivity analysis to assess whether this uncertainty in branch length estimation affected our results and hence our conclusions (Swenson 2009). To do so, we calculated the Pearson's correlation coefficient between the MPD (and MNTD) values based on the phylogenetic tree with polytomies and the MPD (and MNTD) values based on 1000 trees taken at random from the Bayesian posterior distribution of the 10000 fully resolved phylogenetic trees. The sensitivity analysis showed that the MPD and MNTD metrics calculated from the unresolved phylogenetic trees were unbiased estimates. For each family, we found strong correlations $(r>0.9)$ between the MPD (and MNTD) values based on the unresolved tree and the MPD (and MNTD) values based on 1000 randomly resolved trees (Supplementary material Appendix 2, Table A1). We therefore calculated the NRI and NTI indices with the unresolved phylogenetic trees to avoid running the null models with hundreds of randomly resolved trees.

\section{Contemporary and past environmental conditions}

To explain the phylogenetic structure of reef fish assemblages, we used several variables related to contemporary 
environmental conditions and Quaternary environmental change. Building on sea surface temperature and sea level paleo-conditions from sediment cores, we mapped the paleo-distribution of coral reef habitat limited by depth and temperature at a $5 \times 5^{\circ}$ resolution, for the last three million years with a temporal resolution of $1000 \mathrm{yr}$ (see Pellissier et al. 2014 for more details). In particular, we computed two variables both potentially affecting the phylogenetic structure of fish assemblages: 1) the coral reef area per cell of $5 \times 5^{\circ}$ during the 10th percentile of coldest periods and 2) the isolation from coral reef refugia across the Quaternary (see Pellissier et al. 2014 for further details). Current coral reef area has been shown to be a major driver of coral reef fish diversity (Parravicini et al. 2013), as the greater the habitat area, the higher the number of species that can be maintained. We therefore estimated the total coral reef area $\left(\mathrm{km}^{2}\right)$ for each grid cell based on data obtained from the Millenium Coral Reef Mapping project. In order to account also for the potential effect of current biogeographical isolation of coral reefs, a measure of isolation was calculated based on the distance to the nearest coral reef habitat patches (Parravicini et al. 2013). The influence of current climatic conditions was also considered using the current yearly average sea surface temperature for each cell. This information was obtained in the form of raster files from the Bio-ORACLE database at a resolution of 5-arcmin (Tyberghein et al. 2012) available at $\langle$ www.oracle.ugent.be $>$. These estimates are based on monthly mean values (from 2002 to 2009).

\section{Statistical analyses}

We first assessed the relationship between NRI (and NTI) and each of the considered historical (past coral reef area and isolation from Quaternary refugia) and contemporary (current mean sea surface temperature, current coral reef area and current isolation) variables using a bivariate ordinary least squares (OLS) model. We used the coefficient of determination $\left(\mathrm{R}^{2}\right)$ to quantify the proportion of variation in NRI (and NTI) explained by the bivariate linear regression models. To account for potential non-linear associations between NRI (and NTI) and the predictor variables, we tested the quadratic term of each predictor variable. Current coral reef area variable was log-transformed prior analyses. Linear regression models may leave a variable degree of spatial autocorrelation in the residuals, which may bias parameter estimates and affect their statistical significance (Kissling and Carl 2008). We therefore compared the parameter estimates based on a linear regression model to those obtained using a simultaneous autoregressive (SAR) model (Kissling and Carl 2008). A SAR model adjusts for spatial autocorrelation by incorporating a spatially dependent error term.

We then run OLS and SAR models including both contemporary and historical variables. Specifically, we quantified the support for each competing models including all possible combination of contemporary and historical variables by using the Akaike information criterion (AIC; Burnham and Anderson 2002). The probability that a specific model is the best was estimated with the Akaike weight $(\mathrm{w})$ for each subset model (Kissling and Carl 2008). Then, the relative importance of each predictor variable in explaining NRI (and NTI) was assessed by summing Akaike weight values $\left(\mathrm{W}_{\text {AIC }}\right)$ of each subset model including the predictor (Burnham and Anderson 2002). These summed Akaike weights range from 0 to 1 and provide a ranking of predictor variables in terms of information content (Sandel and Dangremond 2011). Finally, we selected the minimum adequate model (MAM) based on the lowest AIC.

To run the univariate and multivariate SAR models, we used a spatial weight matrix with neighbourhoods defined as all cells within $800 \mathrm{~km}$ of the focal cell (i.e. from its centroid), and applied a Moran's I global test to determine whether residual autocorrelation persisted in the SAR models. We used a range of distances (i.e. 800, 1000, 1500 and $2000 \mathrm{~km}$ ) to define the neighbourhood of each grid cell and preliminary analyses showed that only a distance of $800 \mathrm{~km}$ allowed removing spatial autocorrelation in model residuals. The above statistical analyses were performed using the package 'MASS', 'spdep' and 'MuMIn' in R ( $\mathrm{R}$ Development Core Team, $<$ www.R-project.org $>$ ).

\section{Results}

We found contrasted spatial patterns of phylogenetic assemblage structure among families (Table 1 and Fig. 1) with Labridae showing higher values of NRI (Student's t-test: $\mathrm{p}<0.0001$; Supplementary material Appendix 2, Table A2) and NTI (Student's t-test: $p<0.0001$; Supplementary Appendix 2, Table A2) compared to Pomacentridae and Chaetodontidae. In addition, Pomacentridae displayed higher values of NRI (Student's t-test: $p<0.0001$, Supplementary Appendix 2, Table A2) and NTI (Student's t-test: $\mathrm{p}=0.039$; Supplementary material Appendix 2, Table A2) than Chaetodontidae. For each family, the observed patterns of phylogenetic assemblage structure and the relationships between NRI and NTI and the contemporary and historical variables are detailed below.

\section{Pomacentridae}

The phylogenetic structure of the Pomacentridae showed high clustering values around the IAA when considering both NRI and NTI (Fig. 1). A similar result was found when only considering the species pool of the Indo-Pacific region (Fig. 2). In other regions, in the East Pacific and Atlantic,

Table 1. Summary statistics for the net relatedness (NRI) and nearest taxon (NTI) indices calculated for species assemblages belonging to three reef fish families. The first quartile is the data point at the 25th percentile, and the third quartile is the data point at the 75 th percentile.

\begin{tabular}{|c|c|c|c|c|c|c|}
\hline & \multicolumn{2}{|c|}{ Labridae } & \multicolumn{2}{|c|}{ Pomacentridae } & \multicolumn{2}{|c|}{ Chaetodontidae } \\
\hline & NRI & NTI & NRI & NTI & $\mathrm{NRI}$ & NTI \\
\hline Min & -0.968 & -0.146 & -1.859 & -1.648 & -1.335 & -1.462 \\
\hline 1st quartile & 1.557 & 2.684 & -0.725 & 1.639 & -0.548 & 1.664 \\
\hline Median & 1.927 & 3.500 & -0.106 & 2.559 & -0.145 & 2.421 \\
\hline Mean & 1.926 & 3.317 & 1.015 & 2.675 & -0.034 & 2.341 \\
\hline 3rd quartile & 2.431 & 3.976 & 2.884 & 3.886 & 0.628 & 3.367 \\
\hline Max & 4.076 & 6.354 & 6.731 & 6.104 & 1.601 & 4.523 \\
\hline
\end{tabular}


(A)
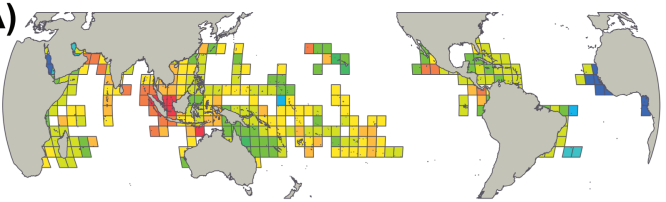

NRI Labridae

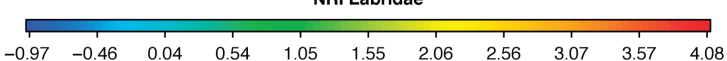

(C)

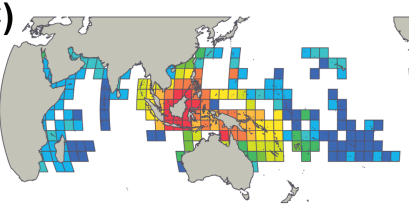

NRI Pomacentridae

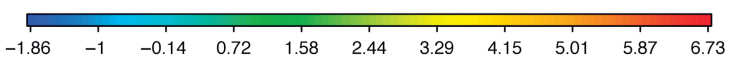

(E)
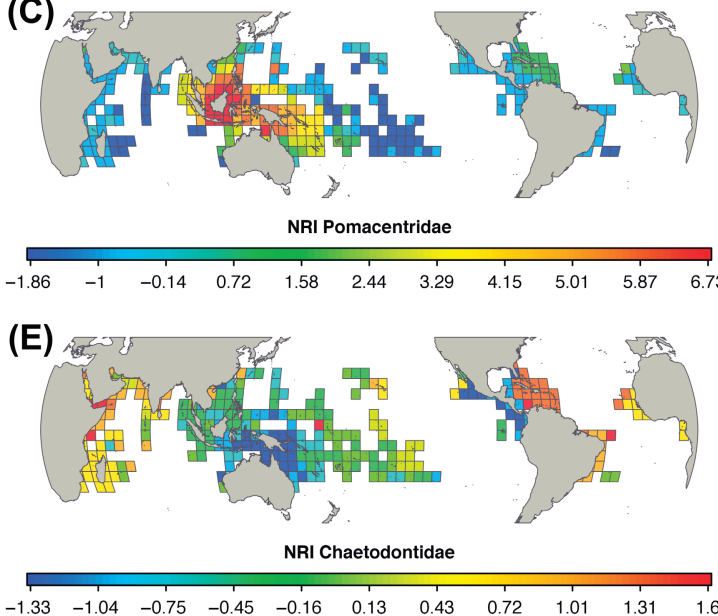

(B)

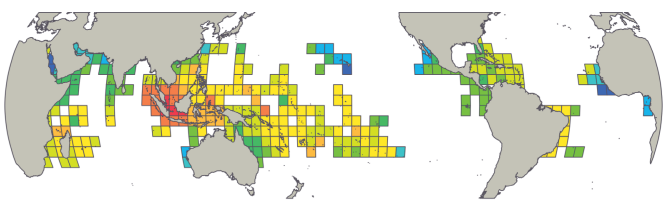

NTI Labridae

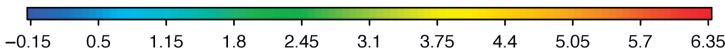

(D)

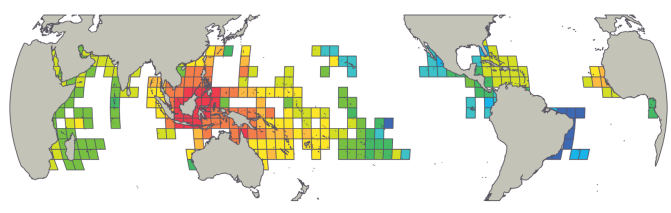

NTI Pomacentridae

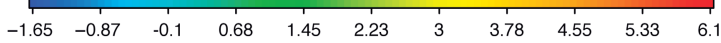

$(\mathrm{F})$
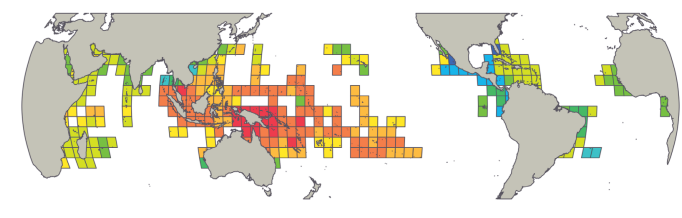

NTI Chaetodontidae

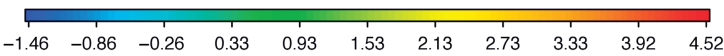

Figure 1. Global distribution of NRI ((A) Labridae, (C) Pomacentridae, (E) Chaetodontidae) and NTI ((B) Labridae, (D) Pomacentridae, (F) Chaetodontidae) values obtained using a null model shuffling the tips of species across the phylogeny. Positive NRI and NTI values indicate phylogenetic clustering while negative values indicate phylogenetic overdispersion. High values of both NRI and NTI were found in the Indo-Australian Archipelago (IAA), also called the coral triangle, which is bounded by the Indonesian archipelago, the Malaysian peninsula, the Philippines, New Guinea and northern Australia.

(A)
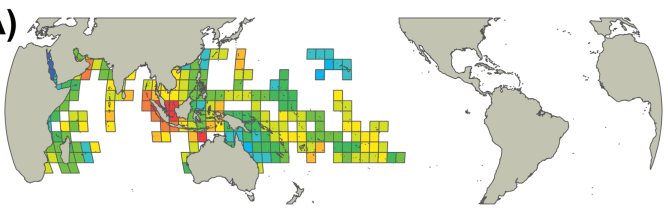

NRI Labridae

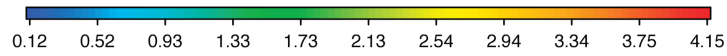

(C)
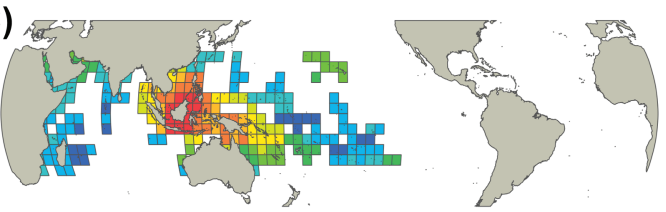

NRI Pomacentridae

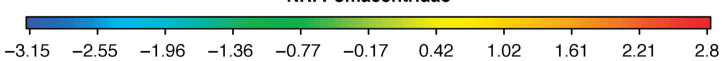

(E)
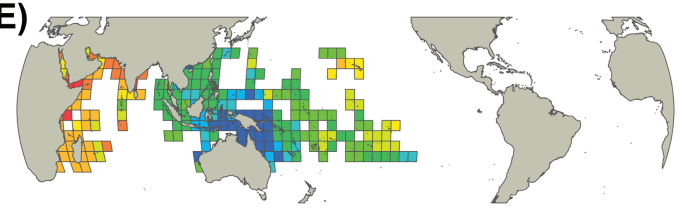

NRI Chaetodontidae

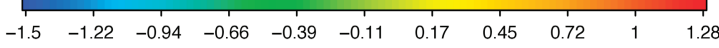

(B)

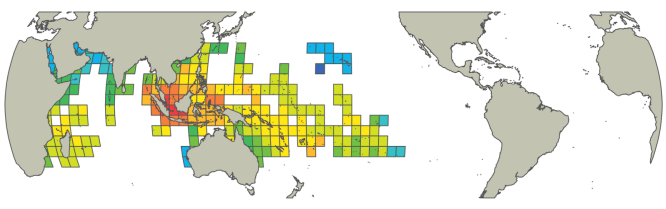

NTI Labridae

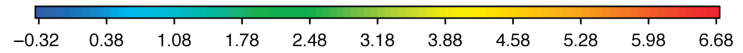

(D)

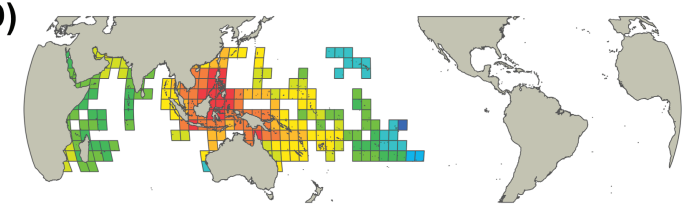

NTI Pomacentridae

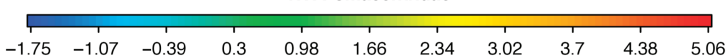

(F)
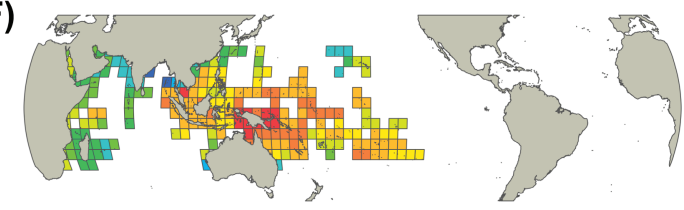

NTI Chaetodontidae

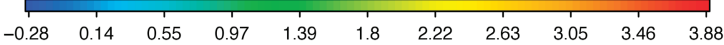

Figure 2. Distribution of NRI ((A) Labridae, (C) Pomacentridae, (E) Chaetodontidae) and NTI ((B) Labridae, (D) Pomacentridae, (F) Chaetodontidae) values obtained using a null model shuffling the tips of species across the phylogeny. The species pool considered here is the Indo-Pacific region (excluding the Tropical Eastern Pacific region and the Atlantic region). Positive NRI and NTI values indicate a phylogenetic clustering while negative values indicate a phylogenetic overdispersion. High values of both NRI and NTI were found in the Indo-Australian Archipelago (IAA), also called the coral triangle, which is bounded by the Indonesian archipelago, the Malaysian peninsula, the Philippines, New Guinea and northern Australia. 
phylogenetic assemblage structure was less distinguishable from random expectations (Fig. 1). Isolation from Quaternary refugia was found to be the most important predictor of both NRI and NTI, i.e. areas closer to Quaternary refugia displayed higher levels of phylogenetic clustering (OLS: $\mathrm{R}^{2}=0.36$ and 0.51 for NRI and NTI, respectively; Supplementary material Appendix 2, Table A3 and A4; Fig. 3). This historical variable also received high support over all subset OLS and SAR models mixing historical and contemporary factors (Table 2 and Supplementary material Appendix 2, Table A5). Current isolation of coral reefs also received high support over all subset OLS and SAR models (Table 2 and Supplementary material Appendix 2, Table A5) but explained less variation in NRI and NTI (OLS: $\mathrm{R}^{2}=0.23$ and 0.28 for NRI and NTI, respectively; Supplementary material Appendix 2, Table A3 and A4).

\section{Chaetodontidae}

The phylogenetic structure of Chaetodontidae showed different spatial patterns for NRI and NTI (Fig. 1). Similar patterns were found when only considering the species pool of the Indo-Pacific region (Fig. 2). NTI showed phylogenetic clustering in the IAA (Fig. 1), a pattern largely explained by the isolation of coral reefs from Quaternary refugia (OLS: $\mathrm{R}^{2}=0.37$; Supplementary material Appendix 2, Table A4; Fig. 3). This historical variable also received high support over all subset OLS and SAR models mixing historical and contemporary factors (Table 2 and Supplementary material Appendix 2, Table A5). Current reef area also received high support over all subset OLS and SAR models (Table 2 and Supplementary material Appendix 2, Table A5) but explained less variation in NTI (OLS: $\mathrm{R}^{2}=0.25$; Supplementary material Appendix 2, Table A4). In contrast, NRI had much less pronounced spatial variation. The IAA showed a weak over-dispersion whereas the Atlantic and the western
Indo-Pacific areas displayed light clustering (Fig. 1). None of the investigated historical and contemporary variables were significantly related to the spatial variation in NRI once spatial autocorrelation has been accounted for with the SAR models (Table 2, Supplementary material Appendix 2, Table A3).

\section{Labridae}

The phylogenetic structure of Labridae showed high clustering values around the IAA when considering both NRI and NTI (Fig. 1), but the highest values occurred predominantly around Thailand and Malaysia peninsula. High clustering was also found in proximity of Madagascar and along the coasts of Brazil. Similar spatial patterns were found when considering only the Indo-Pacific species pool (Fig. 2). Isolation from Quaternary refugia was found to be the most important predictor of NRI (OLS: $\mathrm{R}^{2}=0.18$; Supplementary material Appendix 2, Table A3; Fig. 3) and received high support when considering an OLS model mixing historical and contemporary factors (Supplementary material Appendix 2, Table A5). However, the relationship between NRI and isolation from Quaternary refugia was no longer significant once spatial autocorrelation was accounted for (Table 2 and Supplementary material Appendix 2, Table A3). When considering NTI, isolation from Quaternary refugia and current temperature were found to be the most important predictors of NTI (OLS: $\mathrm{R}^{2}=0.18$ and 0.27 , respectively; Supplementary material Appendix 2, Table A3; Fig. 3). However, only the isolation from Quaternary refugia displayed a significant relationship with NTI once spatial autocorrelation was accounted for (Supplementary material Appendix 2, Table A4). In addition, only the isolation from Quaternary refugia and the current level of isolation of coral reefs received high support when considering a SAR model mixing historical and contemporary factors (Table 2).

Table 2. Results of simultaneous autoregressive (SAR) models relating the net relatedness (NRI) and nearest taxon (NTI) indices for three families (Pomacentridae, Chaetodontidae and Labridae) to several contemporary and historical variables. PRAR, past coral reef area; PISO, isolation from refugia during the Quaternary; RAR, current coral reef area (log-transformed); ISO, current isolation among coral reef cells, TEMP, average sea surface temperature. Shown are the standardized coefficients of the minimum adequate model (MAM) with the lowest AIC score and their statistical significance. The relative importance of each predictor variable was assessed using the summed Akaike weights $\left(\mathrm{W}_{\mathrm{AIC}}\right){ }^{*} \mathrm{p}<0.05,{ }^{* *} \mathrm{p}<0.01, * * * \mathrm{p}<0.001$.

\begin{tabular}{|c|c|c|c|c|c|c|c|c|c|c|c|c|}
\hline & \multicolumn{6}{|c|}{ NRI } & \multicolumn{6}{|c|}{ NTI } \\
\hline & \multicolumn{2}{|c|}{ Labridae } & \multicolumn{2}{|c|}{ Pomacentridae } & \multicolumn{2}{|c|}{ Chaetodontidae } & \multicolumn{2}{|c|}{ Labridae } & \multicolumn{2}{|c|}{ Pomacentridae } & \multicolumn{2}{|c|}{ Chaetodontidae } \\
\hline & MAM & $\mathrm{W}_{\mathrm{AIC}}$ & MAM & $W_{\mathrm{AIC}}$ & MAM & $\mathrm{W}_{\mathrm{AIC}}$ & MAM & $\mathrm{W}_{\mathrm{AIC}}$ & MAM & $\mathrm{W}_{\mathrm{AIC}}$ & MAM & $\mathrm{W}_{\mathrm{AIC}}$ \\
\hline \multicolumn{13}{|c|}{ Historical variables } \\
\hline PRAR & $-0.274^{*}$ & 0.74 & $0.057^{*}$ & 0.77 & & 0.34 & & 0.40 & & 0.40 & & 0.51 \\
\hline $\mathrm{PRAR}^{2}$ & $0.262^{*}$ & 0.64 & & 0.20 & & 0.10 & & 0.16 & & 0.13 & & 0.32 \\
\hline PISO & & 0.42 & $-0.310^{*}$ & 0.83 & & 0.62 & $-0.391^{*}$ & 0.74 & $-0.126^{* *}$ & 0.98 & $-0.155^{* *}$ & 0.91 \\
\hline $\mathrm{PISO}^{2}$ & & 0.16 & 0.171 & 0.51 & & 0.16 & $0.329^{* *}$ & 0.63 & & 0.27 & & 0.25 \\
\hline \multicolumn{13}{|c|}{ Contemporary variables } \\
\hline RAR & & 0.33 & & 0.37 & 0.060 & 0.63 & & 0.36 & 0.038 & 0.62 & $0.078^{*}$ & 0.88 \\
\hline ISO & -0.117 & 0.67 & $-0.123^{* *}$ & 0.97 & -0.289 & 0.84 & $-0.231 * * *$ & 1 & $-0.113^{* *}$ & 0.98 & & 0.56 \\
\hline $\mathrm{ISO}^{2}$ & & 0.27 & & 0.25 & 0.543 & 0.57 & & 0.34 & & 0.28 & & 0.16 \\
\hline TEMP & $0.170^{* *}$ & 0.86 & & 0.33 & & 0.38 & & 0.54 & & 0.37 & 1.476 & 0.97 \\
\hline TEMP2 $^{2}$ & & 0.23 & & 0.09 & & 0.16 & & 0.21 & & 0.10 & -1.375 & 0.60 \\
\hline Moran's I & -0.048 & & -0.025 & & -0.083 & & -0.053 & & -0.087 & & -0.013 & \\
\hline
\end{tabular}


(A)

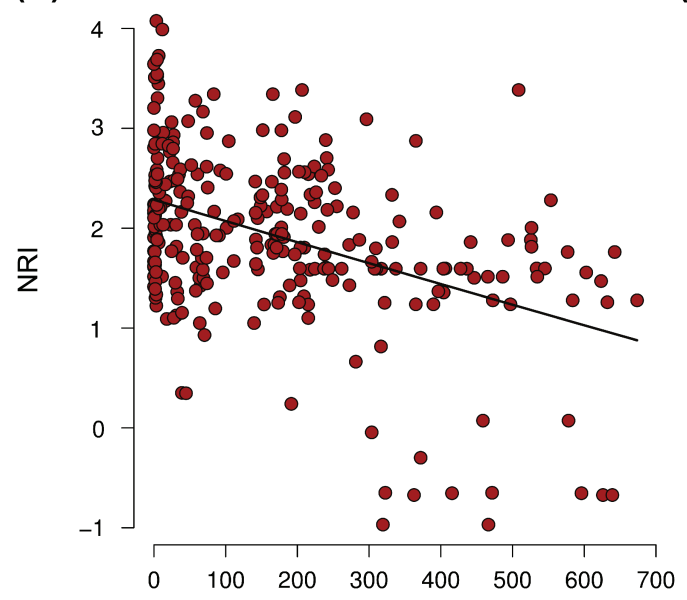

(B)

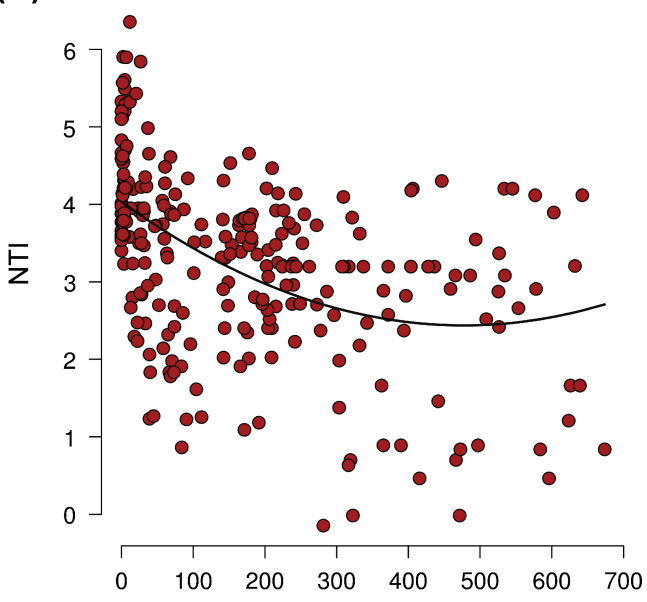

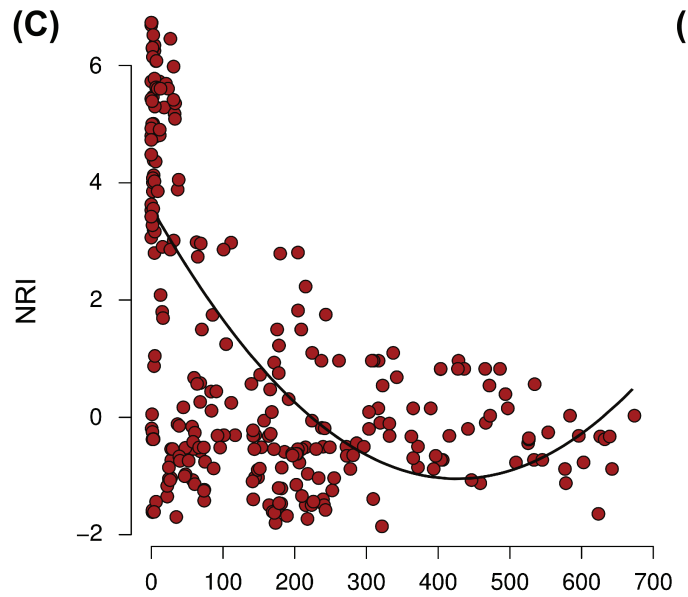

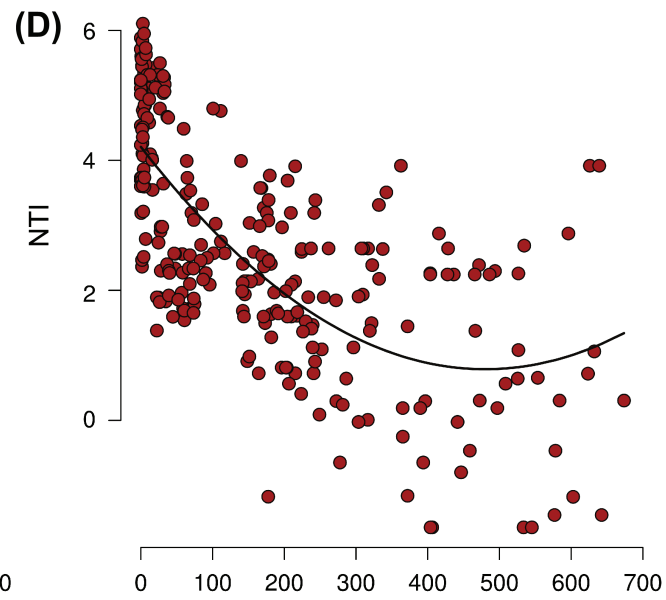

(E)

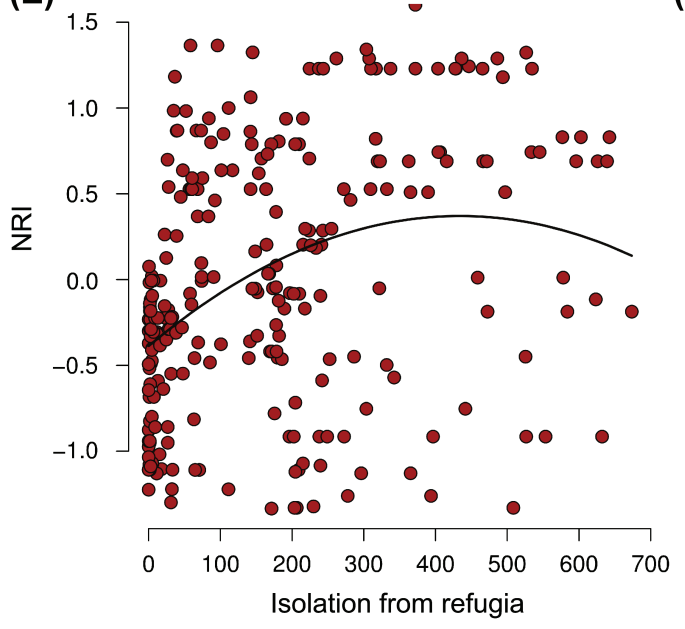

$(\mathrm{F})$

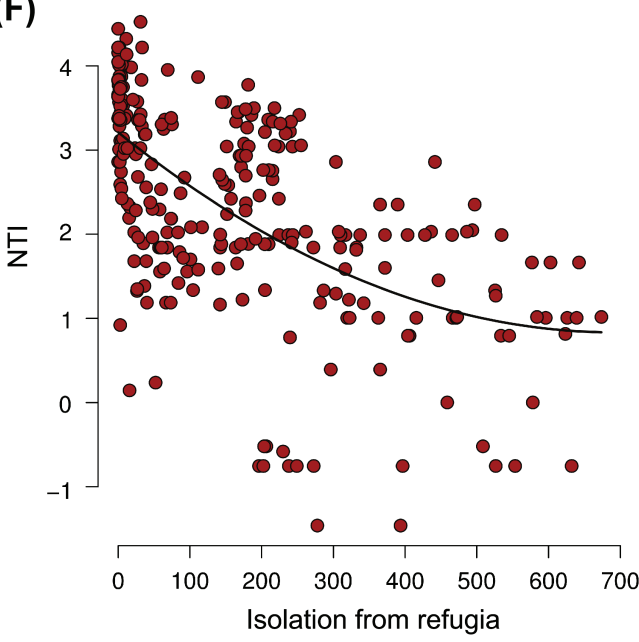

Figure 3. Relationship between NRI ((A) Labridae, (C) Pomacentridae, (E) Chaetodontidae) and NTI ((B) Labridae, (D) Pomacentridae, (F) Chaetodontidae) and isolation from Quaternary coral reef refugia. Solid black lines represent ordinary least squares (OLS) model fits.

\section{Discussion}

Our results revealed high levels of phylogenetic clustering of fish assemblages across the IAA, a pattern also observed for Scleractinian corals by Huang and Roy (2015). Phylogenetic structure at the scale considered in the current study is expected to arise from historical processes (Kissling et al.
2012), but be maintained by the structure of contemporary environment. We found a strong relationship between the phylogenetic structure of fish assemblages and the isolation from refugia during the Quaternary, suggesting that the glacial era played a major role in shaping phylogenetic assemblage structure, especially in the IAA. However, we cannot exclude that phylogenetic clustering may also result from 
tectonic rearrangements during the Miocene, which generated the complex configuration of the archipelago in this area (Renema et al. 2008). Finally, the effect of current isolation of reefs suggests that contemporary processes of dispersal limitation contribute for maintaining the phylogenetic structure of tropical reef fish assemblages.

During cold periods of the Quaternary, coral reefs in the IAA were less extended but also more fragmented than today (Voris 2000, Pellissier et al. 2014, Ludt and Rocha 2015), which may have promoted the formation of species via allopatric or parapatric speciation (McManus 1985, Rocha and Bowen 2008, Ludt and Rocha 2015) resulting from geographic isolation between populations (Coyne and Orr 2004). When glacial cycles ended, fish populations probably expanded from the multiple refugia of the IAA into available coral reef habitat 10-times larger and more connected (Bellwood and Wainwright 2002, Pellissier et al. 2014). Then, sea level dropped $130 \mathrm{~m}$ below current levels during the Pleistocene glacial maxima (Voris 2000), thereby exposing the Sunda and Sahul continental shelves (known also as the Indo-Pacific Barrier) and limiting ocean circulation within the IAA (Gaither and Rocha 2013). This barrier led to allopatric differentiation of populations spanning both the Indian and Pacific Oceans. Following sea-level rise, the geographical ranges of formerly separated sister taxa expanded and hence overlapped in the IAA (Gaither and Rocha 2013). Neutral genetic differentiation during the Pleistocene sea-level fluctuations has been documented for many coral reef taxa across a range of speciation stages (i.e. supra- or infra-species) providing further evidence for this mechanism (Bay et al. 2004, Fitzpatrick et al. 2011, Ludt et al. 2012, Tornabene et al. 2015).

Older isolation processes, not explicitly considered in our study, may also partly explain the observed pattern of phylogenetic clustering in the IAA (Renema et al. 2008, Cowman 2014). For instance, the Indo-Pacific Barrier repeatedly isolated the fish faunas of the Pacific and Indian Oceans as a consequence of eustatic changes in sea level since at least the Pliocene (5.3 mya) (Gaither and Rocha 2013). Also, in the Early Miocene ( 23-16 mya), the Australian plate made contact with the submerged Sundaland and this collision led to closure of the shallow reefs between Sundaland and Australia (Lohman et al. 2011), which increased reef area and the complexity of coral reefs throughout the region. This favoured lineage diversification of coral reef fishes within the IAA at this time (Cowman and Bellwood 2011, 2013a). Tectonic rearrangements during the Miocene may have also promoted vicariance events by restricting water flow between the Indian and Pacific oceans (Renema et al. 2008, Gaither and Rocha 2013). This is consistent with recent studies emphasizing that the majority of speciation events predated the Quaternary period for several coral reef fish families (Cowman 2014, Hodge et al. 2014, Hodge and Bellwood 2015). For instance, the median age of extant species originating in the IAA ranges from 2.45 mya for the Chaetodontidae family to 6.87 and 7.19 mya for the Labridae and Pomacentridae families (Cowman 2014; see also Supplementary material Appendix 2, Table A6). Overall, our results suggest that the high level of phylogenetic clustering of fish assemblages across the IAA result from both the emergence of closely related species and the survival of older sister species during the Quaternary glaciations (McManus 1985, Bellwood and Wainwright 2002, Cowman and Bellwood 2013a, Pellissier et al. 2014). However, complementary studies in the field of historical biogeography are clearly needed to assess the relative importance of old vs. recent historical events in explaining the high level of phylogenetic clustering observed in the IAA.

We compared the phylogenetic structure of fish assemblages among three reef fish families. The likelihood of lineage divergence following allopatric or parapatric speciation should be higher for taxa with limited dispersal capacity sufficient to isolate populations as they are more strongly affected by habitat fragmentation (D'Aloia et al. 2014). In support, Riginos et al. (2014) showed that reef fish speciation rates were associated with fish dispersal abilities. In our analyses, we observed a larger effect of isolation from Quaternary refugia on the phylogenetic structure for the Pomacentridae family compared to Chaetodontidae and Labridae. Pomacentridae have generally low sustained swimming ability of late pelagic stage compared to other fish families and are demersal spawners while the two other families are broadcast. As pelagic eggs cannot actively disperse, larvae retention is expected to be highest for demersal spawners thus reducing their dispersal abilities (Luiz et al. 2012). In addition, Pomacentridae frequently established specialized biotic interaction with species within coral reefs such as anemone, corals or urchins, which limit their colonization abilities of reef where mutualistic organisms are not present (Litsios et al. 2012). In contrast, Labridae have many older lineages (Cowman and Bellwood 2011) with a diverse array of generalist and specialist feeding modes (Cowman et al. 2009). Most of their lineage diversification happened in the Miocene and is linked to the expansion of coral reef habitats during that period. With their high dispersal potential, many labrid lineages would have been able to reach farther refugia before the Quaternary and remained there until dispersal corridors opened up again, which would then have been followed by some vicariance among regions (Cowman and Bellwood 2013b). The influx of those new colonists from other refugia may therefore explain the less marked pattern of phylogenetic clustering for this family. The higher values of NRI and NTI for the Labridae around Thailand and Malaysia as opposed to the central IAA likely reflect a stronger connection between the Central Pacific Islands and the eastern IAA, than the West Indian and western IAA. Overall, differential responses among families therefore suggest that species diversification in the face of historical habitat fragmentation may be shaped by their dispersal abilities.

Our results also revealed contrasted spatial patterns of NRI and NTI for the Chaetodontidae family. High levels of phylogenetic clustering were indeed observed in the IAA when using the NTI metric, which implies that the closest related species are closer than expected by random expectations in this region. In contrast, the use of the NRI metric indicated that species assemblages were weakly overdispersed in the IAA (Fig. 1). It is also worth noting that the NRI metric for the Chaetodontidae shows broadly both low positive and negative values (Fig. 1 and Table 1), hence indicating that the mean phylogenetic distance between species in a given assemblage did not strongly differ from that expected by chance. Such homogeneity in the basal phylogenetic 
structure of species assemblages suggests that dispersal has been important enough to promote the spatial expansion of older lineages of Chaetodontidae throughout tropical oceans (Cowman and Bellwood 2013a). In contrast, the dependence of NTI on terminal branch lengths explains why the terminal phylogenetic structure of species assemblages was found to be more strongly associated to isolation from Quaternary reef refugia, which reflects the high number of divergence events that occurred during the Quaternary period for this family (Cowman 2014, Pellissier et al. 2014). Indeed, Chaetodontidae show significantly younger lineages originating in the IAA when compared to Labridae or Pomacentridae (Cowman 2014; see also Supplementary material Appendix 2, Table A6). These findings emphasize the importance of using complementary phylogenetic metrics of assemblage structure to highlight the legacy of recent or more ancient historical processes on contemporary species assemblages (see also Gonzalez-Caro et al. 2012).

This study supports the important role of historical and evolutionary processes in explaining current patterns of assemblage structure in tropical reef fishes (see also Hubert et al. 2011 at a finer spatial scale). However, this does not imply that local environmental conditions and ecological interactions do not influence the diversity and distribution of tropical reef fishes. The issue of spatial scale is indeed important to consider when exploring patterns and processes of species diversity and assemblage structure (Ricklefs and Schluter 1993, Cavender-Bares et al. 2009) as the relative importance of historical/evolutionary and ecological processes may vary according to the spatial scale considered (Ricklefs 2004). In this study, we defined fish assemblages according to a coarse spatial grain $(555 \times 555 \mathrm{~km})$ and we did not consider local environmental conditions that characterize coral reef ecosystems. Yet, a number of local-scale studies showed that coral reef habitat characteristics (e.g. coral cover, topographic complexity and coral diversity) strongly influence the structure and composition of coral reef fish species assemblages (Komyakova et al. 2013). Overall, we recommend future studies to apply a multi-scale approach (Brunbjerg et al. 2015) by combining both local field inventories (i.e. underwater visual transects) and regional checklists or grid cell distributional data. For instance, a valuable research avenue would be to assess the extent to which history left an imprint on local communities of coral reef fishes.

In this study, we also assessed whether contemporary environmental filtering based on climatic tolerances conserved across lineages was a major process shaping the phylogenetic structure of tropical reef fish assemblages. For the three families considered here, species at higher latitudes were not phylogenetically more related to each other (i.e. phylogenetic clustering) than those at lower latitudes. However, this does not imply that climatic niche conservatism is not an important process structuring marine assemblages (Jablonski et al. 2013). This study is indeed restricted to tropical waters and hence accounts for a lower latitudinal range of temperature. Future works including both temperate and tropical lineages are clearly needed to assess the importance of climate niche conservatism in shaping the phylogenetic structure of fish assemblages in reef systems. Finally, the coverage of the sediment cores was not homogeneous across the tropical seas (Pellissier et al. 2014) and this might have led to uncertainty in the spatial definition of refugia. Future studies should couple several approaches to infer past sea surface temperature including applying temperature anomalies from cores, but also the use of hindcasted climatic models (Sbrocco 2014).

Together, our results highlight the singular phylogenetic structure of tropical reef fish assemblages in the IAA and suggest that phylogenetic clustering is partly associated with Quaternary glaciations, which have created micro-refugia promoting vicariance and allopatric speciation. These findings parallel recent studies showing that climatic fluctuations during the Quaternary also promoted vicariant events in intertidal or fluvial habitats at higher latitudes (Dias et al. 2014, Toms et al. 2014). However, future studies should investigate the role of older processes such as shelves movement following plate tectonic that may also have played a major role in shaping large-scale patterns of tropical marine biodiversity (Keith et al. 2013). To this aim, the development of stochastic simulation models (Gotelli et al. 2009) integrating explicitly the movement of continental shelves through geological time should provide new insights to our understanding of deep time historical processes.

Acknowledgements - This work was supported by the FRB CESAB-GASPAR project.

\section{References}

Barber, P. H. and Bellwood, D. R. 2005. Biodiversity hotspots: evolutionary origins of biodiversity in wrasses (Halichoeres: Labridae) in the Indo-Pacific and new world tropics. - Mol. Phylogenet. Evol. 35: 235-253.

Bay, L. K. et al. 2004. High genetic diversities and complex genetic structure in an Indo-Pacific tropical reef fish (Chlorurus sordidus): evidence of an unstable evolutionary past? - Mar. Biol. 144: 757-767.

Bellwood, D. R. and Wainwright, P. C. 2002. The history and biogeography of fishes on coral reefs. - In: Sale, P. F. (ed.), Coral reef fishes. Dynamics and diversity in a complex ecosystem. Academic Press, pp. 5-32.

Bellwood, D. R. et al. 2005. Environmental and geometric constraints on Indo-Pacific coral reef biodiversity. - Ecol. Lett. 8: 643-651.

Bellwood, D. R. et al. 2010. Evolutionary history of the butterflyfishes (f: Chaetodontidae) and the rise of coral feeding fishes. - J. Evol. Biol. 23: 335-349.

Bowen, B. W. et al. 2013. The origins of tropical marine biodiversity. - Trends Ecol. Evol. 28: 359-366.

Brunbjerg, A. K. et al. 2015. Multi-scale phylogenetic structure in coastal dune plant communities across the globe. - J. Plant. Ecol., doi: 10.1093/jpe/rtt069

Burnham, K. P. and Anderson, D. R. 2002. Model selection and multimodel inference: a practical information-theoretic approach, 2nd ed. - Springer.

Cantalapiedra, J. L. et al. 2014. The biogeographic history of ruminant faunas determines the phylogenetic structure of their assemblages at different scales. - Ecography 37: $1-9$.

Cardillo, M. 2011. Phylogenetic structure of mammal assemblages at large geographical scales: linking phylogenetic community ecology with macroecology. - Phil. Trans. R. Soc. B 366: 2545-2553.

Cavender-Bares, J. et al. 2004. Phylogenetic overdispersion in Floridian oak communities. - Am. Nat. 163: 823-843. 
Cavender-Bares, J. et al. 2009. The merging of community ecology and phylogenetic biology. - Ecol. Lett. 12: 693-715.

Cooper, J. W. et al. 2009. Exploring the radiation of a diverse reef fish family: phylogenetics of the damselfishes (Pomacentridae), with new classifications based on molecular analyses of all genera. - Mol. Phylogenet. Evol. 52: 1-16.

Cowman P. F. 2014. Historical factors that have shaped the evolution of tropical reef fishes: a review of phylogenies, biogeography, and remaining questions. - Front. Genet. 5: 394.

Cowman, P. F. and Bellwood, D. R. 2011. Coral reefs as drivers of cladogenesis: expanding coral reefs, cryptic extinction events, and the development of biodiversity hotspots. - J. Evol. Biol. 24: 2543-2562.

Cowman, P. F. and Bellwood, D. R. 2013a. The historical biogeography of coral reef fishes: global patterns of origination and dispersal. - J. Biogeogr. 40: 209-224.

Cowman, P. F. and Bellwood, D. R. 2013b. Vicariance across major marine biogeographic barriers: temporal concordance and the relative intensity of hard versus soft barriers. - Proc. R. Soc. B 280: 20131541.

Cowman, P. F. et al. 2009. Dating the evolutionary origins of wrasse lineages (Labridae) and the rise of trophic novelty on coral reefs. - Mol. Phylogenet. Evol. 52: 621-631.

Coyne, J. A. and Orr, H. A. 2004. Speciation. - Sinauer.

D'Aloia, C. C. et al. 2014. Seascape continuity plays an important role in determining patterns of spatial genetic structure in a coral reef fish. - Mol. Ecol. 23: 2902-2913.

Dias, M. et al. 2014. Global imprint of historical connectivity on freshwater fish biodiversity. - Ecol. Lett. 17: 1130-1140.

Drummond, A. J. et al. 2012. Bayesian phylogenetics with BEAUti and the BEAST 1.7. - Mol. Biol. Evol. 29: 1969-1973.

Fessler, J. L. and Westneat, M. W. 2007. Molecular phylogenetics of the butterflyfishes (Chaetodontidae): taxonomy and biogeography of a global coral reef fish family. - Mol. Phylogenet. Evol. 45: 50-68.

Fitzpatrick, J. M. et al. 2011. The West Pacific diversity hotspot as a source or sink for new species? Population genetic insights from the Indo-Pacific parrotfish Scarus rubroviolaceus. - Mol. Ecol. 20: 219-234.

Gaither, M. R. and Rocha, L. A. 2013. Origins of species richness in the Indo-Malay-Philippine biodiversity hotspot: evidence for the centre of overlap hypothesis. - J. Biogeogr. 40: 1638-1648.

Gonzalez-Caro, S. et al. 2012. Sensitivity of metrics of phylogenetic structure to scale, source of data and species pool of hummingbird assemblages along elevational gradients. - PLoS One 7: e35472.

Gotelli, N. J. et al. 2009. Patterns and causes of species richness: a general simulation model for macroecology. - Ecol. Lett. 12: 873-886.

Götzenberger, L. et al. 2012. Ecological assembly rules in plant communities: approaches, patterns and prospects. - Biol. Rev. 87: 111-127.

Graham, C. H. et al. 2006. Habitat history improves prediction of biodiversity in rainforest fauna. - Proc. Natl Acad. Sci. USA 103: 632-636.

Graham, C. H. et al. 2009. Phylogenetic structure of hummingbird communities. - Proc. Natl Acad. Sci. USA 106 (Suppl. 2): 19673-19678.

Hodge, J. R. and Bellwood, D. R. 2015. On the relationship between species age and geographical range in reef fishes: are widespread species older than they seem? - Global Ecol. Biogeogr. 24: 495-505.

Hodge, J. R. et al. 2014. Temporal evolution of coral reef fishes: global patterns and disparity in isolated locations. - J. Biogeogr. 41: 2115-2127.

Hoegh-Guldberg, O. et al. 2007. Coral reefs under rapid climate change and ocean acidification. - Science 318: 1737-1742.
Hortal, J. et al. 2011. Ice age climate, evolutionary constraints and diversity patterns of European dung beetles. - Ecol. Lett. 14: 741-748.

Huang, D. and Roy, K. 2015. The future of evolutionary diversity in reef corals. - Phil. Trans. R. Soc. B 370: 20140010.

Hubert, N. et al. 2011. Community assembly and diversification in Indo-Pacific coral reef fishes. - Ecol. Evol. 1: 229-277.

Hughes, T. P. et al. 2003. Climate change, human impacts, and the resilience of coral reefs. - Science 301: 929-933.

Hughes, T. P et al. 2012. Assembly rules of reef corals are flexible along a steep climatic gradient. - Curr. Biol. 22: 736-741.

Jablonski, D. et al. 2013. Out of the tropics, but how? Fossils, bridge species, and thermal ranges in the dynamics of the marine latitudinal diversity gradient. - Proc. Natl Acad. Sci. USA 110: 10487-10494.

Jang-liaw, N. H. et al. 2002. Molecular phylogeny of 48 species of damselfishes (Perciformes: Pomacentridae) using $12 \mathrm{~S} \mathrm{mtDNA}$ sequences. - Mol. Phylogenet. Evol. 25: 445-454.

Kazancioglu, E. 2009. Influence of sexual selection and feeding functional morphology on diversification rate of parrotfishes (Scaridae). - Proc. R. Soc. B 276: 3439-3446.

Keith, S. A. et al. 2013. Faunal breaks and species composition of Indo-Pacific corals: the role of plate tectonics, environment, and habitat distribution. - Proc. R. Soc. B 280: 20130818.

Kissling, D. W. and Carl, G. 2008. Spatial autocorrelation and the selection of simultaneous autoregressive models. - Global Ecol. Biogeogr. 17: 59-71.

Kissling, D. W. et al. 2012. Cenozoic imprints on the phylogenetic structure of palm species assemblages worldwide. - Proc. Natl Acad. Sci. USA 109: 7379-7384.

Komyakova, V. et al. 2013. Relative importance of coral cover, habitat complexity and diversity in determining the structure of reef fish communities. - PLoS One 8: e83178.

Kuhn, T. S. et al. 2011. A simple polytomy resolver for dated phylogenies. - Methods Ecol. Evol. 2: 427-436.

Litsios, G. et al. 2012. Trophic specialization influences the rate of environmental niche evolution in damselfishes (Pomacentridae). - Proc. R. Soc. B 279: 3662-3669.

Lohman D. et al. 2011. Biogeography of the Indo-Australian Archipelago. - Annu. Rev. Ecol. Evol. Syst. 42: 205-226.

Losos, J. B. 2008. Phylogenetic niche conservatism, phylogenetic signal and the relationship between phylogenetic relatedness and ecological similarity among species. - Ecol. Lett. 11: 995-1003.

Ludt, W. B. and Rocha, L. A. 2015. Shifting seas: the impacts of Pleistocene sea-level fluctuation on the evolution of tropical marine taxa. - J. Biogeogr. 42: 25-38.

Ludt, W. B. et al. 2012. Living in the past: phylogeography and population histories of Indo-Pacific wrasses (genus Halichoeres) in shallow lagoons versus outer reef slopes. - PLoS One 7: e38042.

Luiz, O. J. et al. 2012. Ecological traits influencing range expansion across large oceanic dispersal barriers: insights from tropical Atlantic reef fishes. - Proc. R. Soc. B 279: 1033-1040.

Luiz, O. J. et al. 2013. Adult and larval traits as determinants of geographic range size among tropical reef fishes. - Proc. Natl Acad. Sci. USA 110: 16498-16502.

McManus, J. W. 1985. Marine speciation, tectonics, and sea level changes in south-east Asia. - Proc. Fifth Int. Coral Reef Symp. 4: 133-138.

McMillan, W. O. and Palumbi, S. R. 1995. Concordant evolutionary patterns among Indo-West Pacific butterflyfishes. - Proc. R. Soc. B 260: 229-236.

Mittelbach, G. G. et al. 2007. Evolution and the latitudinal diversity gradient: speciation, extinction and biogeography. - Ecol. Lett. 10: 315-331. 
O'Dea, A. et al. 2007. Environmental change preceded Caribbean extinction by 2 million years. - Proc. Natl Acad. Sci. USA 104: 5501-5506.

Pandolfi, J. M. et al. 2011. Projecting coral reef futures under global warming and ocean acidification. - Science 333: 418-422.

Parravicini, V. et al. 2013. Global patterns and predictors of tropical reef fish species richness. - Ecography 36: $1254-1262$.

Pellissier, L. et al. 2014. Quaternary coral reef refugia preserved fish diversity. - Science 344: 1016-1019.

Potts, D. C. 1985. Sea-level fluctuations and speciation in Scleratinia. - Proc. Fifth Int. Coral Reef Congr. Tahiti 4: 127-132.

Qian, H. and Jiang, L. 2014. Phylogenetic community ecology: integrating community ecology and evolutionary biology. - J. Plant Ecol. 7: 97-100.

Quenouille, B. et al. 2004. Molecular systematics of the damselfishes (Teleostei: Pomacentridae): Bayesian phylogenetic analyses of mitochondrial and nuclear DNA sequences. - Mol. Phylogenet. Evol. 31: 66-88.

Read, C. I. et al. 2006. Ancient origins of Indo-Pacific coral reef fish biodiversity: a case study of the leopard wrasses (Labridae: Macropharyngodon). - Mol. Phylogenet. Evol. 38: 808-819.

Renema, W. et al. 2008. Hopping hotspots: global shifts in marine biodiversity. - Science 321: 654-657.

Revell, L. J. 2012. Phytools: an R package for phylogenetic comparative biology (and other things). - Methods Ecol. Evol. 3: 217-223.

Ricklefs, R. E. 2004. A comprehensive framework for global patterns in biodiversity. - Ecol. Lett. 7: 1-15.

Ricklefs, R. E. and Schluter, D. 1993. Species diversity in ecological communities: historical and geographical perspectives. - Univ. Press of Chicago.

Riginos, C. et al. 2014. Dispersal capacity predicts both population genetic structure and species richness in reef fishes. - Am. Nat. 184: 52-64.

Supplementary material (Appendix ECOG-01638 at $<$ www.ecography.org/appendix/ecog-01638>). Appendix 1-2.
Rocha, L. A. and Bowen, B. W. 2008. Speciation in coral reef fishes. - J. Fish Biol. 72: 1101-1121.

Sandel, B. and Dangremond, E. M. 2012. Climate change and the invasion of California by grasses. - Global Change Biol. 18: 277-289.

Sbrocco, E. J. 2014. paleo-MARSPEC: gridded ocean climate layers for the mid-Holocene and Last Glacial Maximum. - Ecology 95: 1710

Smith, L. L. et al. 2008. Phylogenetic relationships and the evolution of regulatory gene sequences in the parrotfishes. - Mol. Phylogenet. Evol. 49: 136-152.

Swenson, N. G. 2009. Phylogenetic resolution and quantifying the phylogenetic diversity and dispersion of communities. - PLoS One 4: e4390.

Tang, K. L. 2001. Phylogenetic relationships among damselfishes. - Copeia 2001: 591- 601.

Toms, J. A. et al. 2014. Variation in palaeo-shorelines explains contemporary population genetic patterns of rocky shore species. - Biol. Lett. 10: 20140330.

Tornabene, L. et al. 2015. Support for a 'Center of Origin' in the Coral Triangle: cryptic diversity, recent speciation, and local endemism in a diverse lineage of reef fishes (Gobiidae: Eviota). - Mol. Phylogenet. Evol. 82: 200-210.

Tyberghein, L. et al. 2012. Bio-ORACLE: a global environmental dataset for marine species distribution modelling. - Global Ecol. Biogeogr. 21: 272-281.

Voris, H. K. 2000. Maps of Pleistocene sea levels in southeast Asia: shorelines, river systems and time durations. - J. Biogeogr. 27: 1153-1167.

Webb, C. O. 2000. Exploring the phylogenetic structure of ecological communities: an example for rain forest trees. - Am. Nat. 156: 145-155.

Webb, C. O. et al. 2002. Phylogenies and community ecology. - Annu. Rev. Ecol. Syst. 33: 475-505.

Wiens, J. J. and Donoghue, M. J. 2004. Historical biogeography, ecology and species richness. - Trends Ecol. Evol. 19: 639-644. 